07

\title{
Гетеробарьерные варакторы с неоднородно легированными модулирующими слоями
}

\author{
() Н.А. Малеев ${ }^{1}$, М.А. Бобров ${ }^{1}$, А.Г. Кузьменков ${ }^{2}$, А.П. Васильев ${ }^{2}$, М.М. Кулагина ${ }^{1}$, Ю.А. Гусева ${ }^{1}$, \\ C.А. Блохин ${ }^{1}$, В.М. Устинов ${ }^{2,3}$ \\ 1 Физико-технический институт им. А.Ф. Иофффе РАН, Санкт-Петербург, Россия \\ ${ }^{2}$ Научно-технологический центр микроэлектроники и субмикронных гетероструктур РАН, Санкт-Петербург, Россия \\ ${ }^{3}$ Санкт-Петербургский государственный электротехнический университет „ЛЭТИ“, Санкт-Петербург, Россия \\ E-mail: maleev@beam.ioffe.ru
}

Поступило в Редакцию 3 июля 2019г.

В окончательной редакции 3 июля 2019г.

Принято к публикации 8 июля 2019 г.

Оптимальная форма вольт-фарадной характеристики является критическим параметром, определяющим эффективность умножения для гетеробарьерных варакторов (ГБВ) миллиметрового и субмиллиметрового диапазонов. Численная модель для расчета вольт-фарадных характеристик и токов утечки ГБВ с произвольным профилем состава и легирования верифицирована на основе опубликованных и оригинальных экспериментальных данных. Спроектированная гетероструктура ГБВ с тремя нелегированными барьерами InAlAs/A1As/InAlAs в окружении неоднородно легированных модулирующих слоев $n$-InGaAs выращена методом молекулярно-пучковой эпитаксии на подложке InP. Тестовые ГБВ, изготовленные из выращенных гетероструктур, демонстрируют близкую к косинусоидальной форму вольт-фарадной характеристики при напряжениях смещения до $2 \mathrm{~V}$, увеличенный коэффициент перекрытия по емкости и низкие токи утечки.

Ключевые слова: гетеробарьерный варактор, вольт-фарадная характеристика, эпитаксия.

DOI: 10.21883/PJTF.2019.20.48396.17960

Гетеробарьерные варакторы (ГБВ), обладающие симметричными вольт-фарадными (ВФХ) и вольт-амперными (BAX) характеристиками, были предложены в качестве альтернативы варакторным диодам с барьером Шоттки при использовании в умножителях частоты миллиметрового и субмиллиметрового диапазонов [1]. Эпитаксиальные гетероструктуры современных ГБВ, как правило, выращиваются методом молекулярнопучковой эпитаксии (МПЭ) на подложках InP и содержат несколько нелегированных барьерных слоев InAlAs/AlAs/InAlAs, расположенных между однородно легированными модулирующими слоями InGaAs $n$-типа [2]. ГБВ на основе таких гетероструктур успешно используются при создании трехкратных и пятикратных умножителей частоты с уровнем непрерывной выходной мощности от сотен $\mathrm{mW}$ в частотном диапазоне около $100 \mathrm{GHz}$ до единиц $\mathrm{mW}$ на частотах вблизи $50 \mathrm{GHz}$ [3]. Одним из ключевых требований к структурам ГБВ является низкий уровень тока утечки при напряжениях, соответствующих максимальной амплитуде входного сигнала. Для снижения токов утечки была предложена конструкция трехбарьерных структур ГБВ с непосредственно примыкающими с двух сторон к гетеробарьеру $\operatorname{In}_{0.52} \mathrm{Al}_{0.48} \mathrm{As} / \mathrm{AlAs} / \mathrm{In}_{0.52} \mathrm{Al}_{0.48} \mathrm{As}$ тонкими рассогласованными слоями InGaAs, испытывающими напряжение сжатия, которые могут частично компенсировать механические напряжения, создаваемые AlAsвставками [4], что позволило добиться рекордно низких уровней тока утечки при одновременном повышении устойчивости технологии выращивания гетерострук- тур [5]. Важнейшей характеристикой, определяющей эффективность работы ГБВ в качестве умножителя частоты, является форма ВФХ. Абсолютное большинство расчетных и экспериментальных работ было выполнено для ГБВ с однородно легированными модулирующими слоями, которые имеют максимальный наклон ВФХ вблизи нулевого напряжения смещения. В то же время в работе [6] предложено использовать в трехкратных умножителях частоты гетероструктуры ГБВ с косинусоидальной формой ВФХ, для которой расчеты предсказывают максимальную эффективность преобразования энергии несущей частоты в энергию утроенной частоты. Однако данные по экспериментальной реализации косинусоидального профиля ВФХ в гетероструктурах ГБВ не публиковались.

В настоящей работе предложен и экспериментально апробирован возможный вариант реализации гетероструктур ГБВ с профилем ВФХ, близким к косинусоидальному в достаточно широком диапазоне напряжений смещения.

Для проектирования структуры ГБВ с косинусоидальным профилем ВФХ необходимо иметь возможности для адекватного расчета ВФХ и ВАХ (токов утечки) гетероструктур ГБВ. Соответствующая модель была реализована в пакете численного моделирования полупроводниковых приборов в рамках использования дрейфово-диффузионной модели для расчета транспорта носителей в структуре ГБВ с учетом термоэлектронной и полевой эмиссии (туннелирования) носителей через гетеробарьеры. При этом влияние кванто- 


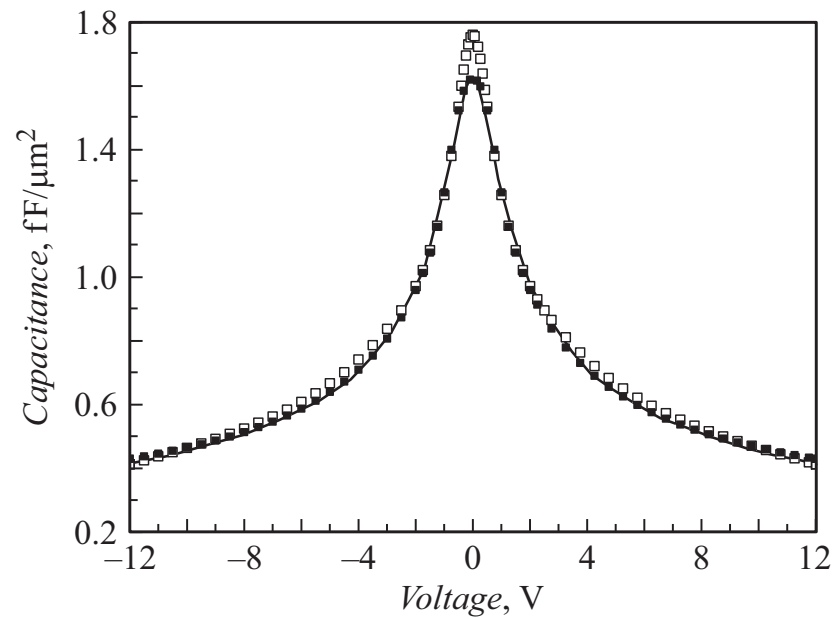

Pис. 1. Экспериментальная ВФХ ГБВ по данным [7] (линия) и расчетные ВФХ для численной модели без учета квантовых эффектов (светлые символы) и при их учете (темные символы).

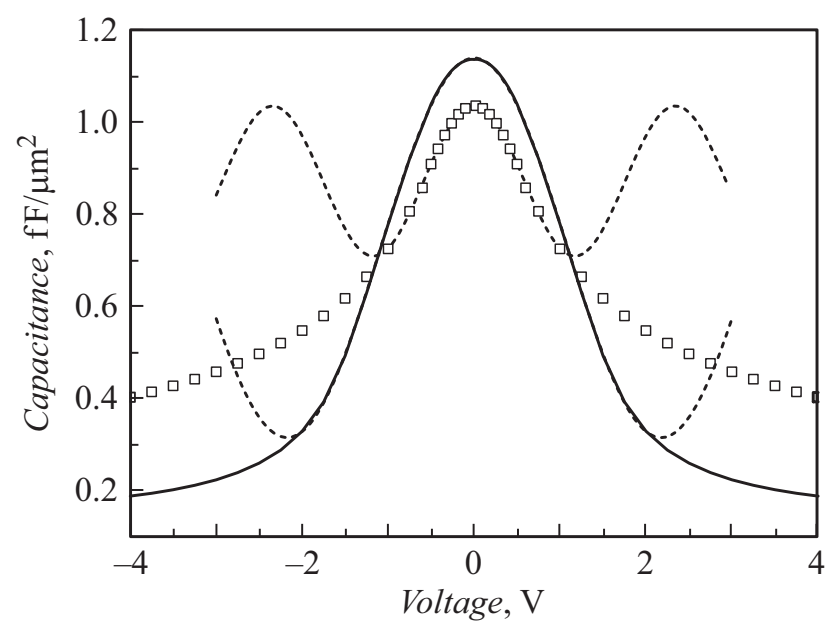

Рис. 2. Расчетные зависимости величины удельной барьерной емкости от напряжения смещения для стандартной гетероструктуры трехбарьерного ГБВ с однородно легированными модулирующими слоями (точки) и предложенной гетероструктуры ГБВ с неоднородно легированными модулирующими слоями (сплошная линия). Штриховыми линиями показаны точные косинусоидальные зависимости барьерной емкости от напряжения.

вых эффектов на транспорт электронов учитывалось за счет использования модели градиента плотности [6]. Разработанная модель была верифицирована на основе опубликованных и оригинальных экспериментальных данных. В качестве примера на рис. 1 приведено сравнение расчетных и экспериментальной зависимостей удельной барьерной емкости от напряжения смещения для структуры ГБВ с двумя барьерными слоями InAlAs/AlAs/InAlAs и однородно легированными модулирующими слоями $n$-InGaAs [7]. При использовании дрейфово-диффузионной модели без учета квантовых эффектов расчеты дают завышенные значения барьерной емкости при малых напряжениях смещения, что приводит к заметному отличию формы ВФХ от полученной экспериментально. В то же время использование модели, учитывающей влияние квантовых эффектов на транспорт электронов, позволяет добиться отличного совпадения расчетных и экспериментальных ВФХ. При этом модель позволяет задавать произвольный профиль состава слоев гетероструктуры и неоднородный профиль легирования.

При проектировании профиля легирования гетроструктуры ГБВ ставилась задача достижения косинусоидальной формы ВФХ для максимального размаха напряжения смещения. На рис. 2 приведены расчетные ВФХ для исследованной ранее [4,5] трехбарьерной структуры ГБВ с модулирующими слоями $n$-InGaAs толщиной $250 \mathrm{~nm}$, однородно легированными кремнием до уровня $2 \cdot 10^{17} \mathrm{~cm}^{-3}$, и для аналогичной структуры с модулирующими слоями, состоящими из последовательности слоев $n$-InGaAs с толщинами 14, 222 и $14 \mathrm{~nm}$ при уровнях легирования $5 \cdot 10^{17}, 2.5 \cdot 10^{16}$ и $5 \cdot 10^{17} \mathrm{~cm}^{-3}$ соответственно. Косинусоидальные зависимости барьерной емкости от напряжения, наложенные на расчетные ВФХ, показывают, что предложенный неоднородный профиль легирования модулирующих слоев обеспечивает практически идеальную косинусоидальную форму ВФХ в диапазоне напряжений смещения $\pm 2 \mathrm{~V}$, а в случае однородного профиля легирования форма расчетной ВФХ близка к косинусоидальной только в диапазоне напряжений смещения $\pm 1 \mathrm{~V}$. При этом коэффициент перекрытия по емкости, рассчитанный как отношение величины удельной барьерной емкости при нулевом напряжении смещения к ее величине при напряжении смещения $\pm 2 \mathrm{~V}$, в случае неоднородного легирования модулирующих слоев превышает 3.5 и существенно превосходит коэффициент перекрытия для структур ГБВ с однородным легированием. Исходя из результатов моделирования ВФХ можно ожидать, что при использовании в утроителях частоты структура ГБВ с неоднородным легированием модулирующих слоев может обеспечить более высокую эффективность умножения при более высоких максимальных значениях амплитуды входного сигнала по сравнению со структурой ГБВ с однородным легированием модулирующих слоев.

Спроектированная гетероструктура ГБВ с тремя нелегированными барьерами InAlAs/AlAs/InAlAs в окружении неоднородно легированных модулирующих слоев $n$-InGaAs была выращена методом МПЭ на подложке InP в одной серии со структурами ГБВ стандартной конструкции с однородно легированными модулирующими слоями. Во всех структурах использовалась предложенная ранее конструкция барьерных слоев с частичной компенсацией механических напряжений [4,5]. Для измерения ВФХ и ВАХ на выращенных гетероструктурах изготавливались тестовые ГБВ с размерами мезы от $50 \times 50$ до $150 \times 150 \mu \mathrm{m}$. Измерения ВФХ проводились на частоте $1 \mathrm{MHz}$ с использованием прецизионного 

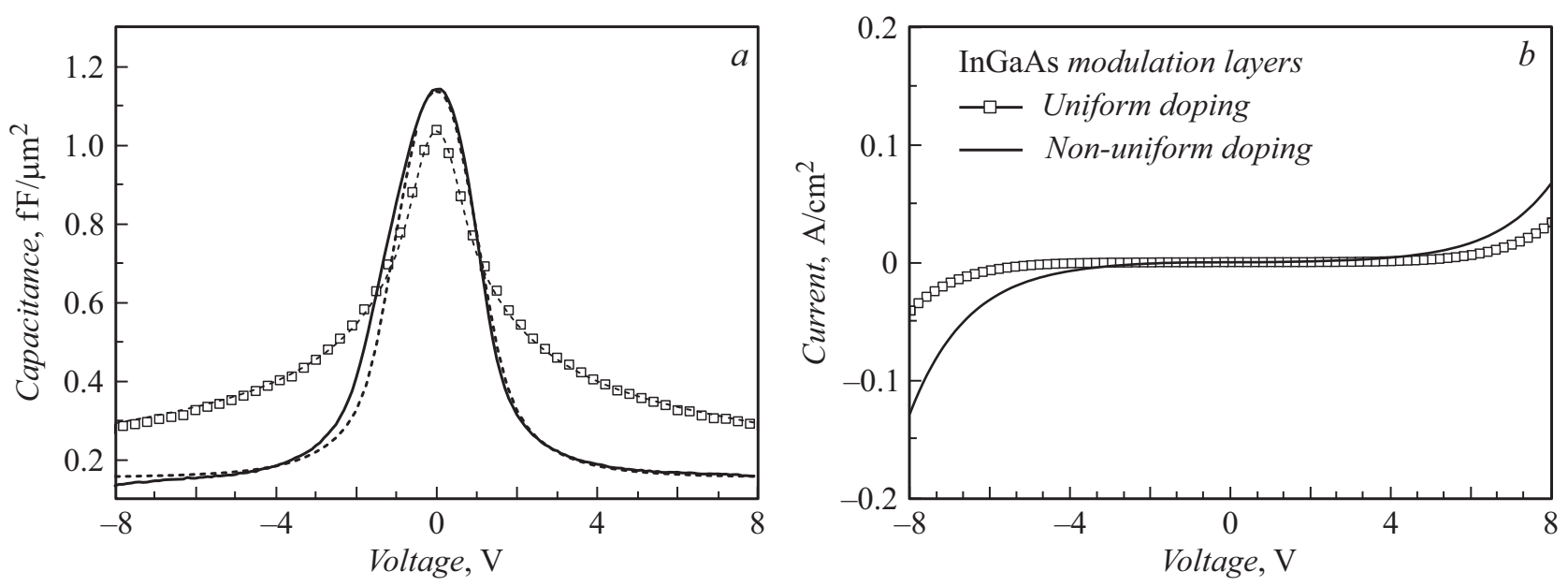

Pис. 3. $a$ - экспериментальные ВФХ тестовых ГБВ на основе трехбарьерных гетероструктур с однородно легированными (точки) и неоднородно легированными (сплошная линия) модулирующими слоями, штриховыми линиями показаны соответствующие расчетные ВФХ; $b-$ экспериментальные ВАХ для тех же структур.

LRC-измерителя E4980 Agilent. Измерения токов утечки осуществлялись с помощью прецизионного источникаизмерителя Keithley 2401.

На рис. 3, а приведены результаты измерения ВФХ структур ГБВ с однородным и неоднородным легированием модулирующих слоев $n$-InGaAs, а также результаты расчетов ВФХ для структур двух типов при номинальных значениях параметров слоев эпитаксиальных гетероструктур. Экспериментальные ВФХ близки к расчетным и подтверждают возможность реализации косинусоидальной формы ВФХ на структурах с неоднородным легированием модулирующих слоев. При этом диапазон значений напряжения смещения, в котором ВФХ хорошо описывается косинусоидальной зависимостью, существенно шире, чем в случае структур ГБВ с однородным легированием модулирующих слоев. Анализ ВАХ тестовых диодов, изготовленных из структур двух типов, показывает (рис. $3, b$ ), что уровень токов утечки для структур с неоднородным легированием модулирующих слоев $n$-InGaAs несколько выше, однако по абсолютным значениям токи утечки малы и не превосходят уровня токов утечки для успешно применяемых в умножителях структур ГБВ с конструкцией барьерных слоев без частичной компенсации механических напряжений [5]. При этом в случае неоднородно легированных модулирующих слоев на экспериментальных ВФХ и BAX наблюдается некоторая асимметрия. Она может быть связана с особенностями формирования профиля легирования в процессе МПЭ при использовании двух источников кремния, поскольку при открывании заслонок молекулярных источников неизбежно наблюдаются переходные процессы [8]. Уровень легирования на границах отдельных слоев в пределах модулирующих слоев $n$-InGaAs с неоднородным легированием резко меняется примерно на порядок, поэтому профили легирования при переходе от высокого уровня легирования к низкому и обратно могут несколько различаться. Данный вопрос требует дополнительных исследований для корректировки режима эпитаксиального выращивания и получения практически симметричных ВФХ и ВАХ, как это наблюдается в случае структур ГБВ с однородно легированными модулирующими слоями.

Полученные результаты подтверждают хорошую точность численной модели, использованной для расчета вольт-фарадных характеристик и токов утечки структур ГБВ с произвольным профилем состава и легирования. Тестовые диоды, изготовленные из выращенной методом МПЭ гетероструктуры ГБВ с тремя нелегированными барьерами InAlAs/AlAs/InAlAs в окружении неоднородно легированных модулирующих слоев $n$-InGaAs, демонстрируют близкую к косинусоидальной форму ВФХ в большем диапазоне напряжений, увеличенный коэффициент перекрытия по емкости и низкие токи утечки.

\section{Финансирование работы}

Работа выполнена при поддержке Российского фонда фундаментальных исследований (проект № 16-29-03346 офи_м).

\section{Конфликт интересов}

Авторы заявляют, что у них нет конфликта интересов.

\section{Список литературы}

[1] Kollberg E., Rydberg A. // Electron. Lett. 1989. V. 25. P. 1696 1697.

[2] Malko A., Bryllert T., Vukusic J., Stake J. // 24th Int. Conf. Indium Phosphide and Related Materials. Santa Barbara, USA, 2012. P. 92-94.

[3] Stake J., Malko A., Bryllert T., Vukusic J. // Proc. IEEE. 2017. V. 105. P. 1008-1019. 
[4] Малеев Н.А., Беляков В.А., Васильев А.П., Бобров М.А., Блохин С.А., Кулагина М.М., Кузьменков А.Г., Неведомский В.Н., Гусева Ю.А., Малеев С.Н., Ладенков И.В., Фефелова Е.Л., Фефелов А.Г., Устинов В.М. // ФТП. 2017. T. 51. B. 11. C. $1484-1488$.

[5] Малеев Н.А., Бобров М.А., Кузьменков А.Г., Васильев А.П., Кулагина М.М., Малеев С.Н., Блохин С.А., Неведомский В.Н., Устинов В.М. // Письма в ЖТФ. 2018. Т. 44. B. 19. C. 16-23.

[6] Wettstein A., Schenk A., Fichtner W. // IEEE Trans. Electron Dev. 2001. V. 48. P. 279-284.

[7] Carbonell J., Boria V.E., Lippens D. // Microwave Opt. Technol. Lett. 2008. V. 50. P. 474-479.

[8] Gozu S., Mozume T., Kuwatsuka H., Ishikawa H. // Nanoscale Res. Lett. 2012. V. 7. P. 620. 